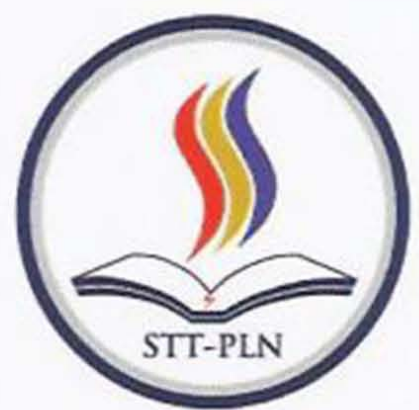

Adhitya Ilham Ramdhani

Arief Suardi Nur Chairat

Dian Hartanti

Faisal Piliang: Silvester Dian Handy Permana Indah Handayasari; Hamzah Mujahid

Iriansyah BM Sangadji

Karina Djunaidi

Ghoniy Rosyiddin; Kikim Mukiman

Rahma Farah Ningrum

Sarwo; Wiwit

Shinta Esabella: Iskandar Fitri

Yessy Asri
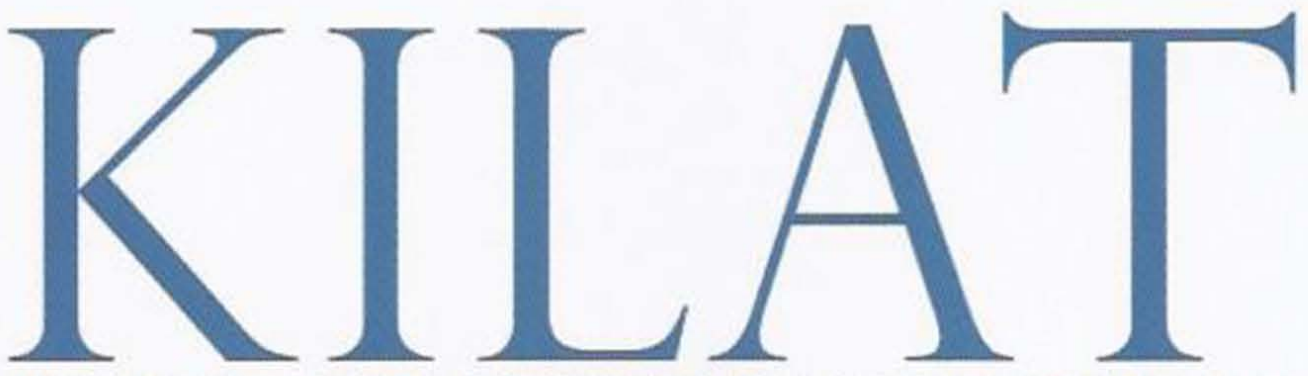

JURNAL KAJIAN ILMU DAN TEKNOLOGI
ANALISA DAN PERANCANGAN ELECTRONIC CUSTOMER RELATIONSHIP MANAGEMENT (E-CRM) DALAM MENINGKATKAN LOYALITAS PELANGGAN PADA PT. PENTA ARTHA IMPRESSI

IMPLEMENTASI PENERAPAN METODE SIX SIGMA PADA PROSES PERAKITAN ELEKTRO MOTOR (STUDI KASUS: PT. TATUNG ELECTRIC INDONESIA)

PERANCANGAN APLIKASI PEMANTAU KEAMANAN BERDASARKAN PERGERAKAN MENGGUNAKAN KONEKSI EMAIL, HANDPHONE DAN VIDEO

STRATEGI OPTIMASI DALAM MENENTUKAN LINTASAN TERPENDEK UNDIVIDED RAGNAROK ASSAULT PROBLEM (UNDIVIDED GAMES)

EVALUASI DAMPAK BANGUNAN SEMENTARA ARRIVING SHAFT PADA PEMBANGUNAN TEROWONGAN PENGENDALI BANJIR (SUDETAN) KALI CILIWUNG KE KANAL BANJIR TIMUR

ANALISIS SURVEY TRACER STUDI PROGRAM STUDI TEKNIK INFORMATIKA STRATA 1 SEKOLAH TINGGI TEKNIK PLN TAHUN 2014

PERENCANAAN STRATEGI TI DAN PENERAPANNYA PADA KOMISI AKREDITASI RUMAH SAKIT

SISTEM ANTI VIRUS MENGGUNAKAN METODE CYCLIC REDUNDANCY CHECKSUM-32 "GnR-AV"

IMPLEMENTASI MANAJEMEN ASSET PADA TIANG DISTRIBUSI LISTRIK JARINGAN TEGANGAN RENDAH DAN JARINGAN TEGANGAN MENENGAH DENGAN MEMANFAATKAN APLIKASI QGIS (QUANTUM GEOGRAPHIC INFORMATION SYSTEM)

PERANCANGAN SISTEM BERBASIS FUZZY LOGIC UNTUK DEDUPLIKASI PENUNJANG KEPUTUSAN KELAYAKAN NASABAH PADA LEASING PT. CS FINANCE

ANALISA DAN PERANCANGAN INFRASTRUKTUR JARINGAN KOMPUTER UNTUK MENDUKUNG PENGEMBANGAN IMPLEMENTASI ELECTRONIC GOVERNMENT (STUDI KASUS PEMERINTAH KABUPATEN SUMBAWA BARAT)

PEMANFAATAN WEB SERVICE SEBAGAI INTEGRASI DATA PADA TATA LAKSANA LABORATORIUM KOMPUTER (STUDI KASUS LAB.KOMPUTER LANJUT INFORMATIKA STT-PLN)

\begin{tabular}{|l|l|l|l|l|l|}
\hline KILAT & VOL.4 & NO.2 & HAL.120-218 & OKTOBER 2015 & ISSN 2089 - 1245 \\
\hline
\end{tabular}




\title{
IMPLEMENTASI PENERAPAN METODE SIX SIGMA PADA PROSES PERAKITAN ELEKTRO MOTOR (STUDI KASUS: PT. TATUNG ELECTRIC INDONESIA)
}

\author{
Arief Suardi Nur Chairat \\ Jurusan Teknik Mesin STT-PLN Jakarta \\ J. Lingkar Luar Barat, Duri Kosambi, cengkareng, Jakarta Barat, 11750 \\ E-Mail: ariefsuardi.nc@gmail.com
}

\begin{abstract}
PT. Tatung Electric Indonesia is a peripatetic company in manufacturing industry assembling of electro motor. So that product yielded by PT. Tatung Electric Indonesia can continue to fulfill requirement of customer, company try to improve the quality of its product by minimizing defect which during the time still happened. This defect arising caused by the existence of variation at yielded product and a'so that happened in the process. Six Sigma represent control technique or method to reach storey or level quality of 3.4 DPMO (Defects Per Million Opportunities), which applied by Motorola company since year 1986. Applying strategy to be used is Define-Measure-Analyze-Improve-Control (DMAIC). This Method represent recuring step and form a make-up of quality cycle. Calculations show the company is 3.641 sigma level with DPMO 15,830. The sigma levels are on the average level of sigma industries in Indonesia (3-4 sigma). Increased levels of sigma would happen if the company immediately continuous improvement over time. Conclusion of the application of Six Sigma is the DMAIC method in the assembly process of electro motors can analyze and reduce disability that occurs that will increase the quality of products.
\end{abstract}

Keywords: Six sigma, Quality, Define-Measure-Analyze-Improve-Control

\begin{abstract}
Abstrak
PT. Tatung Electric Indonesia merupakan perusahaan yang bergerak dalam industri manufaktur perakitan elektro motor. Agar produk elektro motor yang dihasilkan dapat terus memenuhi kebutuhan pelanggan, perusahaan berusaha meningkatkan kualitas produknya dengan cara meminimasi kecacatan yang selama ini masih terjadi. Kecacatan ini timbul karena disebabkan adanya variasi pada produk yang dihasilkan maupun yang terjadi dalam proses. Six Sigma merupakan metode atau teknik pengendalian untuk mencapai tingkat kualitas 3,4 DPMO (Defects Per Million Opportunities), yang diterapkan oleh perusahaan Motorola sejak tahun 1986. Strategi penerapan yang akan digunakan adalah DefineMeasure-Analyze-Improve-Control (DMAIC). Metode ini merupakan tahapan yang berulang dan membentuk suatu siklus peningkatan kualitas. Perhitungan menunjukkan level sigma perusahaan adalah 3,641 dengan DPMO sebesar 15.830. Tingkat sigma tersebut berada pada tingkat rata-rata industri sigma di Indonesia (3-4 sigma). Peningkatan level sigma akan terjadi jika perusahaan segera perbaikan terus-menerus dari waktu ke waktu. Kesimpulan dari penerapan metode Six Sigma adalah metode DMAIC dalam proses perakitan elektro motor dapat mengidentifikasi dan mengurangi kecacatan yang akan meningkatkan kualitas produk.
\end{abstract}

Kata kunci: Six sigma, Kualitas, Define-Measure-Analyze-Improve-Control 


\section{PENDAHULUAN}

Dalam menghadapi persaingan pasar bebas yang semakin ketat, setiap perusahaan menerapkan berbagai macam cara agar produkproduk mereka dapat terus bertahan. Untuk mewujudkan hal tersebut, kualitas dari produkproduk tersebut merupakan elemen penting yang harus diperhatikan. Banyak perusahaan manufaktur mengabaikan kualitas untuk mendapatkan keuntungan jangka pendek yang dicapai dengan tingkat produksi yang tinggi. Kualitas merupakan segala sesuatu yang memuaskan pelanggan / pembeli dan sesuai dengan kebutuhan. Dengan melakukan pengendalian kualitas (quality control) secara baik dan benar, maka akan dihasilkan produk yang dapat memenuhi keinginan konsumen. Disamping itu perusahaan dapat terus bersaing serta mempertahankan kelangsungan hidup dan menjaga profitabilitas perusahaan tersebut. Salah satu cara agar perusahaan dapat meningkatkan kualitas produk adalah dengan menerapkan metodologi Six Sigma. Six Sigma adalah sebuah pengukuran, dimana menghitung defect-defect yang terjadi di dalam sebuah proses dan hasilnya ditampilkan dalam bentuk angka atau grafik yang mendorong kita melakukan improvement (Pyzdek, 2001). Melaksanakan Six Sigma tidak hanya mengeliminasi hampir semua cacat, rework, dan scrap, tetapi juga mempertahankan efisiensi produksi dengan menggunakan sumber daya manusia dan modal yang tersedia.

PT, Tatung Electric Indonesia merupakan perusahaan yang bergerak dalam industri manufaktur perakitan elektro motor atau motor listrik. Agar produk yang dihasilkan oleh PT. Tatung Electric Indonesia dapat terus memenuhi kebutuhan pelanggan, perusahaan berusaha meningkatkan kualitas produknya dengan cara meminimasi kecacatan yang selama ini masih terjadi. Kecacatan ini timbul karena disebabkan adanya varisasi pada produk yang dihasilkan maupun yang terjadi dalam proses. Variasi ini harus dikurangi karena semakin kecil variasi yang terjadi akan semakin disukai karena menunjukkan konsistensi dalam kualitas. Untuk mengetahui dan mengenalisa penyebab variasivariasi yang terjadi, perusahaan mencoba menerapkan progran peningkatan kualitas secara terus-menerus, karena selama ini perusahaan belum menggunakan alat-alat statistik dalam menetapkan tindakan perbaikan dan pencegahan dalam proses perakitan. Dengan diterapkannya program peningkatan kualitas tersebut diharapkan proses akan menuju tingkat kesempurnaan (kegagalan nol) peningkatan kapabilitas sigma (sigma level), serta peningkatan kapabilitas proses sehingga sasaran perusahaan untuk dapat terus memenuhi dan memuaskan keinginan pelanggan dapat tercapai.

\section{METODOLOGI PENELITIAN}

Metodologi penelitian yang digunakan dalam penelitian ini adalah kualitatif dan kuantitatif yaitu dengan melakukan studi pendahuluan dengan cara melakukan pengamatan langsung terhadap kondisi perusahaan dan wawancara dengan beberapa karyawan pabrik serta pihak yang bersangkutan. Selain itu juga dilakukan pengumpulan data melalui pengamatan langsung dan wawancara dengan pihak perusahaan. Adapun data-data yang dikumpulkan adalah data sekunder dan data primer. Data sekunder terdiri dari : (1) sejarah umum perusahaan, (2) kebijakan perusahaan, (3) struktur organisasi perusahaan, dan (4) proses perakitan elektro motor. Sedangkan data primer adalah : (1) data produksi harian, (2) data tingkat dan frekuensi cacat, (3) data jenis cacat, dan (4) data aliran proses dan input output proses. Tahapantahapan metodologi penelitian dapat dlihat pada gambar di bawah ini. 


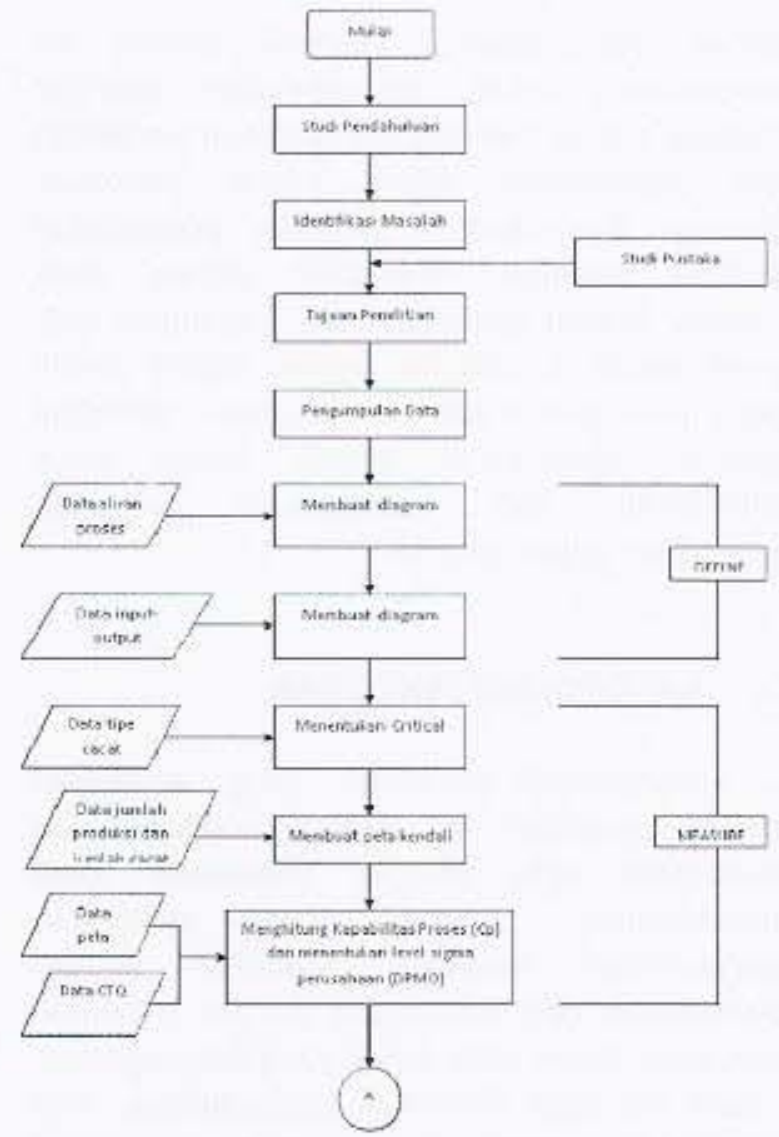

Gambar 1. Flowchart metodologi penelitian

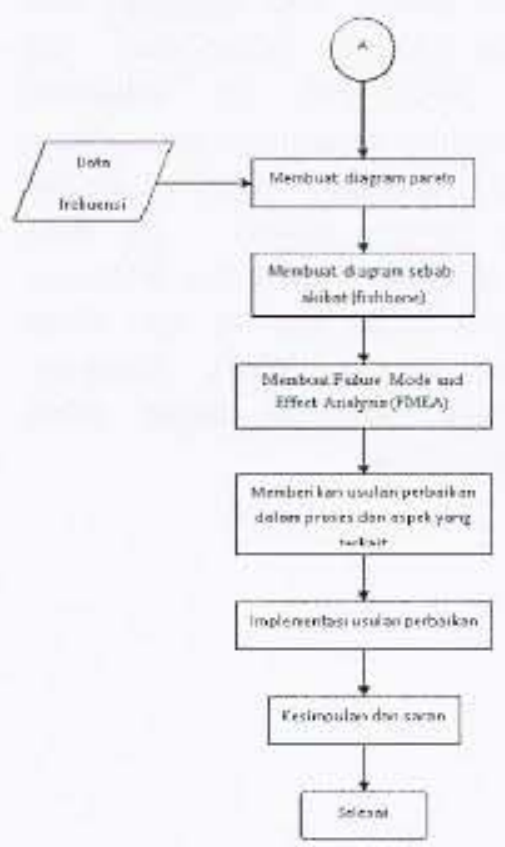

Gambar 2. Lanjutan flowchart metodologi penelitian

\section{HASIL DAN PEMBAHASAN}

Terdapat lima tahapan yang akan dilakukan sesuai dengan strategi penerapan Six Sigma, yaitu Define-Measure-Analyze-Improve-Control (DMAIC). Tahapan-tahapan ini merupakan tahapan yang berulang atau membentuk siklus peningkatan kualitas dengan Six Sigma. Tahapan Define merupakan tahap pertama dalam model DMAIC dan dari tahapan ini akan diketahui bagaimana aliran proses yang ada, input-input apa saja yang dibutuhkan dalam tahapan persiapan sehingga proses akan berjalan dengan baik, sehingga akan menghasilkan ouput-output yang sesuai dengan yang diharapkan oleh perusahaan. Salah satu alat yang digunakan pada tahapan ini adalah diagram input-processoutput.

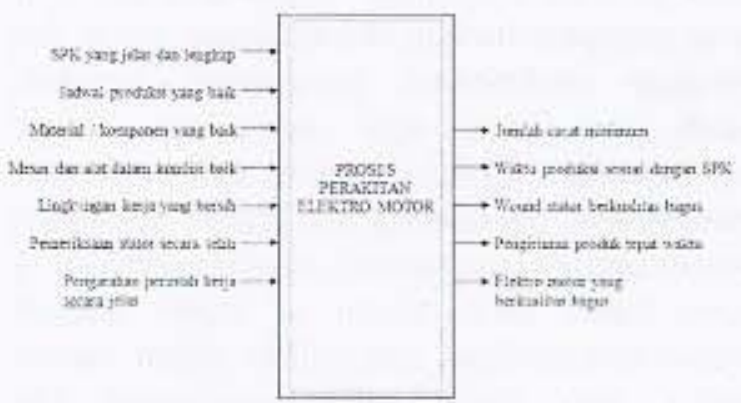

Gambar 3. Diagram input-process-output

Tahapan Measure bertujuan untuk melakukan pengukuran terhadap fakta-fakta yang akan menghasilkan data, dan akan berguna sebagai pengetahuan bagi pihak manajemen untuk meningkatkan kualitas. Tingkat kapabilitas proses menentukan apakah suatu proses mampu atau tidak dalam memenuhi target yang ingin dicapai. Perhitungannya adalah sebagai berikut :

Nilai Center Line $(C L) / \bar{p}$ pada peta kendali $p=0,1425$

Indeks kapabilitas proses

$$
=1-\bar{p}=1-0,1425=0,8575
$$

Dari perhitungan ternyata diperoleh indeks kapabilitas proses kurang dari 1. Hal ini menunjukkan bahwa proses tidak mampu untuk memenuhi target spesifikasi yang telah ditentukan masih rendah atau dengan kata lain kapabilitas prosesnya rendah, sehingga perlu 
dilakukan tindakan-tindakan perbaikan agar kapabilitasnya dapat meningkat. Tujuan menentukan atau menetapkan karakteristik kualitas / Critical to Quality adalah untuk mengetahui karakteristik-karakteristik yang mempunyai kemungkinan atau berpotensi menjadi defect / cacat pada hasil akhir. Karakteristik yang kritis adalah semua jenis cacat yang mungkin terjadi pada tahapan proses perakitan elektro motor 1 HP di PT. Tatung Electric Indonesia, yaitu kontak bodi, ampere tidak rata, salah putaran, gesekan, putaran lambat, getaran besar, dengung listrik, suara bearing, dan rotor oblak. Jumlah CTQ untuk tahapan proses perakitan berjumlah sembilan karakteristik dan jumlah CTQ inilah yang akan digunakan untuk menghitung nilai defect per million opportunities (DPMO).

Perhitungan DPMO menunjukkan bahwa level sigma berada pada tingkat 3,641 sigma dengan DPMO sebesar 15.830 . Tingkat sigma tersebut berada pada rata-rata tingkat sigma industri-industri di Indonesia ( 3 - 4 sigma). sedangkan rata-rata industri kelas dunia adalah 5-6 sigma.

Setelah melakukan tahap Define serta Measure, tahap selanjutnya adalah tahap analisa atau Analyze. Tahap ini merupakan langkah untuk menentukan faktor-faktor utama penyebab variasi dan pencarian akar penyebab masalah, sehingga dapat meningkatkan tahapan proses yang sedang berlangsung Alat-alat yang digunakan adalah diagram pareto untuk mengetahui cacat dominan yang terjadi serta diagram fishbone guna mengetahui sebabsebab dan akibat terjadinya variasi.

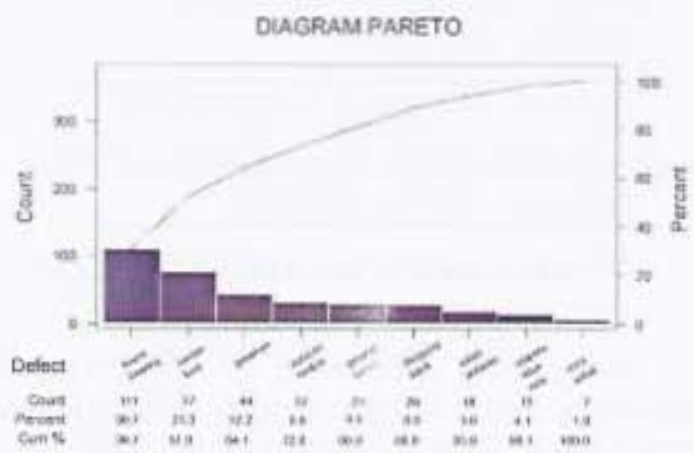

Gambar 4. Diagram pareto jenis cacat (Periode Januari - Maret)

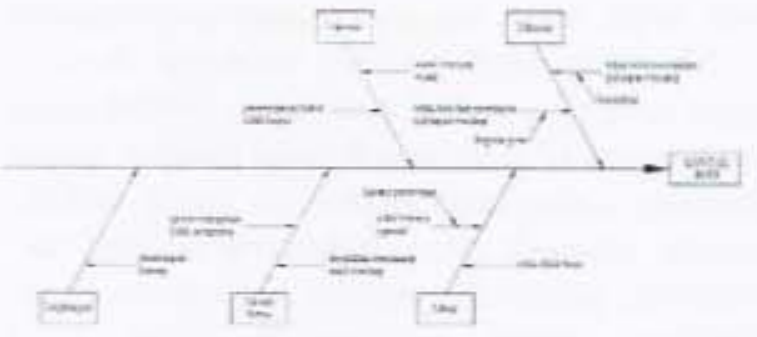

Gambar 5. Diagram Fishbone Untuk Jenis Cacat Kontak Bodi

Tahapan Improve merupakan langkah operasional keempat dalam program peningkatan kualitas Six Sigma. Tahap ini akan membantu untuk memperbaiki atau meningkatkan proses. Alat yang digunakan pada tahap ini adalah Failure Mode Effect and Analysis (FMEA), untuk mengetahui penyebab-penyebab potensial dari masalah yang ada. Dalam FMEA akan dilakukan perhitungan Risk Priority Number (RPN), yang merupakan perkalian dari nilai Occurrence (O), Severity (S), Detectability (D) dengan memberikan nilai secara subyektif antara 1-10 sebagai kriterianya.

Tabel 1. Foilure Mode and Effect Anolysis Untuk Jenis Cacat Kontak Bod:

\begin{tabular}{|c|c|c|c|c|c|c|c|}
\hline $\begin{array}{l}\text { let: } \\
\text { peropman }\end{array}$ & $\begin{array}{l}\text { Modis } \\
\text { iegaprian } \\
\text { peaterat }\end{array}$ & $\begin{array}{l}\text { Poperet } \\
\text { nivel }\end{array}$ & 0 & s & 0 & 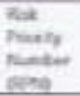 & Adsonerices \\
\hline 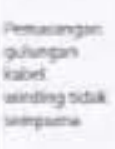 & Idikintin & 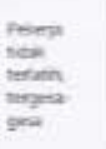 & 5 & s & $\mathrm{s}$ & 150 & 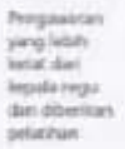 \\
\hline 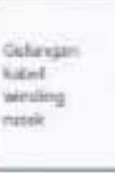 & $\begin{array}{l}\text { changan } \\
\text { lextien }\end{array}$ & 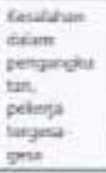 & 4 & 4 & 1 & $4=$ & 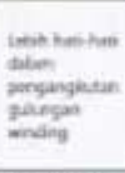 \\
\hline 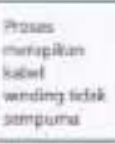 & $\begin{array}{l}\text { lidek } \\
\text { komermast }\end{array}$ & 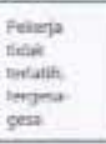 & 4 & 5 & 4 & so & 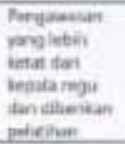 \\
\hline $\begin{array}{l}\text { Mein tidat } \\
\text { lekery } \\
\text { aptimat }\end{array}$ & & $\begin{array}{l}\text { Kerang } \\
\text { petumican }\end{array}$ & 3 & 4 & 4 & 44 & 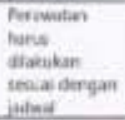 \\
\hline $\begin{array}{l}\text { Cosdahan } \\
\text { mamanary } \\
\text { mall wretiog }\end{array}$ & & $\begin{array}{l}\text { Deverias } \\
\text { nda } \\
\text { teich } \\
\text { sergess } \\
\text { gese }\end{array}$ & 4 & 5 & 7 & 50 & 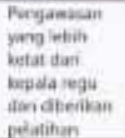 \\
\hline
\end{tabular}

Setelah sumber-sumber dan akar penyebab dari masalah kualitas teridentifikasi dari pembuatan diagram pareto, diagram fishbone, 
dan FMEA, maka harus dilakukan usulan-usulan untuk menangani masalah, terutama masalah yang menjadi prioritas. Pada tahap kontrol, yang merupakan langkah operasional terakhir dalam program peningkatan kualitas Six Sigma, usulanusulan tersebut akan didokumentasikan dan dijadikan pedoman standar kerja perusahaan. Sehingga target peningkatan sigma yang diharapkan, dapat terwujud secara bertahap. Usulan-usulan yang dibuat adalah berdasarkan faktor-faktor penyebab kegagalan dari diagram fishbone serta usulan-usulan instruksi kerja untuk tahapan proses pembuatan elektro motor.

Tujuan dilakukannya implementasi terhadap proses perakitan elektro motor $1 \mathrm{HP}$ adalah untuk mengetahui apakah terjadi perbedaan sebelum dan sesudah melakukan usulan-usulan perbaikan serta usulan instruksi kerja yang telah diberikan. Untuk mengetahui perbedaan yang terjadi sebelum dan sesudah melakukan usulan perbaikan, maka akan dilakukan pengujian secara statistik. Uji yang akan digunakan adalah uji selisih antara dua proporsi, karena karena data-data tersebut berbentuk proporsi. Proporsi yang diuji adalah proporsi cacat selama bulan Maret dengan proporsi cacat setelah implementasi. Selama bulan Maret, jumlah produksi elektro motor 1 HP menghasilkan 765 unit dengan jumlah cacat sebanyak 109 buah. Taraf nyata yang digunakan adalah 0,05 serta $p_{1}$ menyatakan proporsi total cacat sebelum implementasi dan $p_{2}$ menyatakan proporsi total cacat setelah implementasi, berikut adalah langkah-langkah perhitungannya:

1. $H_{0}: p_{1}=p_{2}$

2. $H_{0}: p_{1}>p_{2}$

3. $\alpha=0.05$

4. Wilayah Kritik: $Z>1,645$

5. Perhitungan:

$$
\begin{gathered}
\hat{p}_{1}=\frac{x_{1}}{n_{1}}=\frac{109}{765}=0,1425 \\
\hat{p}_{2}=\frac{x_{2}}{n_{2}}=\frac{14}{168}=0,0833 \\
\hat{p}=\frac{x_{1}+x_{2}}{n_{1}+n_{2}}=\frac{109+14}{765+168}=0,1318 \\
z=\frac{\hat{p}_{1}-\hat{p}_{2}}{\sqrt{\hat{p} \hat{q}\left[\left(1 / n_{1}\right)+\left(1 / n_{2}\right)\right]}}
\end{gathered}
$$

$$
\begin{aligned}
& =\frac{0,1425-0,0833}{\sqrt{(0,1318)(0,8682)[(1 / 765)+(1 / 168)]}} \\
& =2,052
\end{aligned}
$$

Kesimpulan : Tolak $H_{0}$, berarti proporsi cacat setelah implementasi lebih kecil daripada proporsi cacat sebelum implementasi.

Disamping melakukan uji proporsi, untuk mengetahui berhasil atau tidaknya usulanusulan perbaikan yang diterapkan pada proses, juga harus dihitung DPMO atau level sigma setelah implementasi. Dengan melakukan perhitungan ini akan diketahui apakah konsep Six Sigma yang diterapkan meningkatkan level sigma perusahaan. Perhitungannya dapat dilihat seperti di bawah ini :

- Unit (U)

Jumlah elektro motor 1 HP yang diproduksi selama tanggal bulan April adalah sebanyak 168 unit.

- Opportunities (OP)

Karakteristik yang kritis (Critical to Quality) yang terjadi dalam proses berjumlah 9 karakteristik.

- Defect (D)

Defect yang terjadi dalam proses perakitan elektro motor 1 HP selama bulan April sebanyak 14 defect.

- Defect Per Unit (DPU)

$$
\begin{aligned}
& D P U=D / U \\
& D P U=14 / 168=0,0833
\end{aligned}
$$

- Total Opportunities (TOP)

$$
\begin{aligned}
& T O P=U \times O P \\
& T O P=168 \times 9=1.512
\end{aligned}
$$

- Defect Per Opportunities (DPO)

$$
\begin{aligned}
& D P O=D / T O P \\
& D P O=14 / 1.512=0,009259
\end{aligned}
$$

- Defect Per Million Opportunities (DPMO)

$$
\begin{aligned}
& D P M O=D P O \times 1000000 \\
& D P M O=0.009259 \times 1000000=9.259
\end{aligned}
$$

Dari Tabel Konversi Six Sigma, yang tercantum dalam lampiran, nilai DPMO sebesar 9.259 berada diantara 9.137 DPMO (3.86 sigma) dan 9.387 DPMO (3,85 sigma). Dengan menggunakan interpolasi, maka didapatkan: 


$$
\begin{aligned}
& \frac{9.259-9.137}{9.387-9.259}=\frac{x-3,85}{3,86-x} \\
& 250 x=963,72 \\
& x=3,855
\end{aligned}
$$

\section{KESIMPULAN DAN SARAN}

\subsection{Kesimpulan}

Berdasarkan hasil-hasil pengolahan data dan analisa yang telah dilakukan, dapat ditarik beberapa kesimpulan, yaitu :

1. Pada tahapan proses perakitan elektro motor di PT. Tatung Electric Indonesia, terdapat sembilan jenis karakteristik kualitas / jenis cacat yang terjadi. Hal ini merupakan permasalahan yang dihadapi oleh perusahaan untuk dapat meningkatkan kualitas produknya. Jenisjenis cacat tersebut adalah: (1) Kontak bodi, (2) Ampere tidak rata, (3) Salah putaran, (4) Gesekan, (5) Putaran lambat, (6) Getaran besar, (7) Dengung listrik, (8) Suara bearing, dan (9) Rotor oblak.

2. Berdasarkan pembuatan peta kendali $p$ menunjukkan bahwa kondisi proses sudah stabil atau dapat dikatakan proses berada dalam pengendalian statistik, karena tidak ada data-data yang berada di luar batas kontrol. Berarti, variasi yang terjadi dalam proses disebabkan cleh penyebab umum (common cause).

3. Indeks kapabilitas proses perusahaan mempunyai nilai 0,8575 atau kurang dari 1 . Berarti proses belum mampu untuk memenuhi target spesifikasi yang telah ditentukan atau kapabilitas proses rendah. Harus dilakukan tindakan-tindakan perbaikan agar kapabilitasnya meningkat.

4. Perhitungan Defect per Million Opportunities (DPMO) menunjukkan level sigma perusahaan berada 3,641 sigma dengan DPMO 15.830. Tingkat sigma tersebut berada pada rata-rata tingkat sigma industri-industri di Indonesia $(3-4$ sigma). Peningkatan level sigma akan terjadi jika perusahaan segera melakukan perbaikan secara terus-menerus dari waktu ke waktu.
5. Secara garis besar faktor-faktor yang menyebabkan terjadinya cacat-cacat pada proses perakitan elektro motor $1 \mathrm{HP}$ adalah : (1) Adanya kesalahan dalam proses kerja, (2) Pemasangan salah satu material atau komponen sehingga menyebabkan gangguan pada material yang lain, (3) Kualitas material atau komponen yang tidak bagus, dan (4) Sebagian pekerja yang belum terlatih untuk melakukan tahapan proses sesuai dengan instruksi kerja.

\subsection{Saran}

Sebagai bagian akhir dari penelitian, maka akan diberikan beberapa saran kepada PT. Tatung Electric Indonesia agar menjadi masukan yang bermanfaat. Saran-saran tersebut adalah:

1. Mendukung penerapan program Six Sigma sebagai modal tetap dalam meraih keunggulan kualitas serta meningkatkan kinerja organisasi, sehingga dapat terus memenuhi kebutuhan pelanggan.

2. Menerapkan dan memfokuskan program Six Sigma dalam semua level perusahaan, yaitu business level, operation level, dan process level. Melalui cara ini, maka akan terjadi peningkatan integrasi, proses pembelajaran, serta pertukaran pengetahuan-pengetahuan baru dalam perusahaan.

\section{DAFTAR PUSTAKA}

Gaspersz, Vincent. 2002. Pedoman Implementasi Program SIX SIGMA - Terintegrasi dengan 150 9001: 2000, MBNQA, dan HACCP. PT. Gramedia Pustaka Utama, Jakarta.

Miranda, ST dan Drs. Amin Widjaya Tunggal, AK, MBA. 2002. Six Sigma - Gambaran Umum, Penerapan Proses dan Metode-Metode yang Digunakan untuk Perbaikan GE Motorola. Harvarindo, Jakarta.

Modul Praktikum QC, Teknik Industri Universitas Trisakti. Jakarta,

Pande, P.S., Robert P. Neuman, Roland R. Cavanagh. 2000. The Six Sigma Way - How GE, Motorola, and Other Top Companies are Honing Their Performance. McGraw-Hill, Inc., New York. 
Pyzdek, T. 2001. The Six Sigma Handbook Panduan Lengkap untuk Greenbelts, Blackbeits, dan Manajer pada Semua Tingkat. PT. Salemba Emban Patria, Jakarta.
Walpole, Ronald E. 1993. Pengantar Stotistika. PT. Gramedia Pustaka Utama, Jakarta. 